\title{
REPRESENTASI VISUAL PRASI UNTUK MEMPERTAHANKAN KEARIFAN LOKAL MASYARAKAT BALI PADA ERA DISRUPTIF 4.0
}

\author{
Novian Wahyu Firmansyah ${ }^{1,}$ Andika Agung Sutirsno ${ }^{2}$, Pujiyanto ${ }^{3}$, Andhika Putra \\ Herwanto ${ }^{4}$ \\ Desain Komunikasi Visual, Seni dan Desain,Universitas Negeri Malang ${ }^{1234}$ \\ e-mail : novian.firmansyah.fs@um.ac.id, andika.agung.fs@um.ac.id, pujiyanto.fs@um.ac.id, \\ andhika.putra.fs@um.ac.id
}

\begin{abstract}
Existence is a fundamental need to maintain local wisdom in the era of disruption 4.0. The Balinese people still maintain prasi work, which is to carve a visual form palm leaves using a penguprak. The phenomenological approach is used to allocate the data analysis obtained. In the development of technology in the current digitalization era, the existence of traditional works is at stake. Not avoiding, but must adapt, compromise with technological developments into a strategy. Visual representation is the starting point in seeing the existence of designs that have appeared in prasi work in the current digitalization era. The form of visual design builds positive perceptions in maintaining traditional art to be an essential part of prasi work. Digitalization using technology is important to maintain the existence of prasi works, because this work can be widely informed by documents in digital form.
\end{abstract}

Keywords: prasi, design, visual, disruption 4.0, existence

\begin{abstract}
Abstrak: Eksistensi merupakan kebutuhan yang mendasar untuk mempertahankan kearifan lokal di era disrupsi 4.0. Masyarakat Bali masih mempertahankan berkarya prasi, yakni menorehkan wujud visual pada daun lontar dengan menggunakan penguprak (sebuah pisau kecil). Pendekatan fenomenologi digunakan untuk mengalokasikan analisis data yang diperoleh. Dalam perkembangan teknologi di era digitalisasi saat ini, eksistensi karya tradisi sangat dipertaruhkan. Bukan menghindar akan tetapi harus beradaptasi, kompromi dengan perkembangan teknologi menjadi strategi. Representasi visual menjadi titik awal dalam melihat keberadaan desain yang muncul pada karya prasi pada era digitalisasi saat ini, wujud desain secara visual membangun persepsi positif dalam mempertahankan seni tradisi menjadi hal esensial dari karya prasi. Digitalisasi menggunakan teknologi menjadi penting mempertahankan eksistensi karya prasi, dikarenakan karya ini dapat diinformasikan secara luas dengan dokumen yang berbentuk digital. Selain itu, diharapkan penelitian ini dapat memberikan inspirasi bagi karya-karya tradisional lainnya dapat bertahan di era disrupsi 4.0 ini dengan memanfaatkan digitalisasi, tidak hanya di Bali, namun juga di daerah-daerah lainnya di Indonesia.
\end{abstract}

Kata Kunci: prasi, desain, visual, disrupsi 4.0, eksistensi

\section{PENDAHULUAN}

Kesusastraan Bali merupakan kekayaan masyarakat Bali karena semuanya sangat berhubungan dengan seni dan budaya, serta keadaan sosial masyarakat Bali. Kesusastraan Bali adalah hasil daya cipta manusia (pengarang) berdasarkan ilham atau wahyu yang kemudian ditulis menggunakan bahasa yang baik (Gautama, 2007, p.27). Kesusastraan Bali Sebagian besar bersifat imajinatif. Kesusastraan Bali tersebut terbagi dua, yaitu sastra Bali Purwa dan sastra Bali Anyar. Berdasarkan konvensinya prasi termasuk dalam karya sastra Bali Purwa. Prasi merupakan salah satu budaya tulis di atas daun lontar yang

$\begin{array}{ll}\text { Received on } & : 15 / 05 / 2020 \\ \text { Revised on } & : 20 / 12 / 2020 \\ \text { Accepted on } & : 23 / 03 / 2021\end{array}$ 
berbentuk naskah ilustrasi. Secara fisik, prasi terdiri dari tulisan (naskah cerita) dan gambar (gambar ilustrasi). Tulisan yang digunakan dalam prasi adalah huruf Bali. Ilustrasi yang melengkapi tulisan dibuat dengan gaya wayang. Prasi ini dibuat dengan cara khusus, menggunakan alat khusus, yaitu sejenis pisau.

Perkembangan

teknologi

komunikasi saat ini berkembang pesat. Perkembangan ini juga mempengaruhi industri media. Media dituntut untuk dapat beradaptasi dengan perkembangan teknologi komunikasi. Teknologi yang terjadi di era industri 4.0, disruptif dalam berbagai bentuk media terjadi terutama pada media informasi. Paradigma baru akan berbagai hal yang konvensional terjadi dengan pergeseran makna terhadap media. Berkaitan dengan ini, globalisasi media telah mengakibatkan perubahan ciri umum diplomasi dan komunikasi internasional. Dov Shinar (2000, p. 83) menunjukkan bahwa pertukaran internasional pada tahun 1990-an memiliki dua karakteristik pembangunan utama: Pertama, adanya tuntutan dan gerakan separatis, iklim pasca-Perang dingin membuat upaya perdamaian lebih sulit. Persis seperti konflik antara Timur Tengah dan Irlandia Utara. Kedua, peran media dalam hubungan internasional telah mengalami perubahan besar. Karya tradisional jurnalis telah diperluas dengan mencakup pengumpulan dan pemilihan fakta, konstruksi, pengkodean, dan representasi realitas. Disrupsi mengacu pada konsep tertentu dari "kehancuran", atau tindakan yang mengarah pada perpecahan (Dru, 2007, p. 1). Sebagai semacam "tindakan", harus ada metode yang jelas. Ini adalah masalah interupsi yang dihadapi belakangan ini, karena "perpecahan" adalah tindakan sabotase yang tidak disadari, yang dianggap "sudah pecah", tetapi tidak mungkin untuk menganalisis apakah perilaku tersebut diterima atau tidak, terutama karena disrupsi.
Menurut Piliang (dalam Raharja, 2012: 1) Di satu sisi, globalisasi dipandang sebagai peluang eksplorasi diri. Di sisi lain, globalisasi dipandang sebagai ancaman bagi budaya lokal, termasuk local designe dan keberlanjutan budaya lokal itu sendiri. Menurut Atmaja (dalam Raharja, 2012:1) Budaya dan masyarakat tradisional Bali tidak dapat menghentikan globalisasi, karena Bali adalah bagian dari dusun global. Bahkan masyarakat Bali akan mengalami perubahan yang pesat secara terusmenerus. Apalagi sejak zaman penjajahan, turis asing sudah banyak berkunjung ke Bali, apalagi sejak 1927 Perusahaan Perkapalan Belanda (KPM) mengundang turis Eropa ke Bali. Piliang (2005, p. 5) menjelaskan bahwa melalui proses penafsiran kembali budaya lokal untuk mendapatkan makna baru tanpa mengubah nilai esensinya, budaya lokal dapat dikembangkan untuk mencapai prestasi yang luar biasa. Itu tidak mengecualikan konsep perlintasan estetika, tetapi memperkaya makna dengan menggabungkan dua budaya. Melalui proses komunikasi lintas budaya yang selektif tanpa merusak nilai dan identitas budaya lokal dapat diperoleh makna baru dan unik. Dengan membuka diri secara kritis, menerima budaya eksternal yang positif dan menyaring budaya eksternal yang negatif, budaya lokal tidak akan dirugikan. Salah satu contoh karya visual hasil dari komunikasi lintas budaya yaitu lukisan yang menggambarkan pertemuan barong Bali dan barongsai China dengan latar penari bali dalam pemeran tunggal lintas bangsa bertajuk "Culture in Colours" di Santrian Gallery Sanur, 28 Juni hingga 9 Agustus 2019 oleh Perupa Djaja Tjandra Kirana. Karya seni rupa yang dipamerkan mengusung konten akulturasi budaya lintas bangsa khususnya Bali dan China.

Kearifan lokal merupakan esensi khas yang bisa menjadi penciri dari karya desain. Dalam perkembangan 
desain yang terjadi di Indonesia disrupsi dalam desain terjadi terutama pada gaya desain, gaya desain yang terjadi di Indonesia saat ini sangat terpengaruh oleh gaya desain dari luar. Hal ini terjadi akibat disrupsi era 4.0 yang memberikan informasi secara global. Akan tetapi apakah desainer Indonesia mendapat edukasi dalam memanfaatkan kearifan local dalam berkarya pada jenjang pendidikan? Ini menjadi pertanyaan yang mendasar dari penelitian dengan melibatkan perguruan tinggi dalam negeri lain, institut seni indonesia denpasar dipilih sebagai rekanan dalam penelitian ini dengan pertimbangan institusi ini memiliki akreditasi A dan program studi Desain Komunikasi Visual-nya juga memiliki akreditasi A dari BANPT. Perguruan tinggi pada jurusan desain komunikasi visual menjadi perhatian khusus dalam konteks penelitian ini, bagaimana edukasi dalam menerapkan kearifan lokal pada proses desain untuk mempertahankan eksistensi kearifan lokal dalam era disrupsi saat ini.

\section{METODE}

Penelitian ini menggunakan metode penelitian deskriptif kualitatif dengan kolaborasi kerjasama Universitas Negeri Malang dan institut Seni Indonesia Denpasar. Moustakas (1994) dan Patton (2002) mengemukakan beberapa pandangan teoritis berdasarkan metode kualitatif, yaitu fenomenologi (fenomenologi), interaksi simbolik, etnografi (etnografi), heuristik (penyelidikan heuristik) dan Hermeneutika. Metode dalam penelitian ini menggunakan pendekatan fenomenologi.

Istilah fenomenologi berasal dari kata Yunani "fenomena", yang berarti "menunjukkan diri" (to show itself). Sejak 1765, istilah tersebut telah digunakan dalam diskusi filosofis, khususnya Immanuel Kant. Namun bagi Hegel, arti teknis dari istilah tersebut berarti "pengetahuan yang tampak dalam kesadaran". Pengetahuan di sini berarti apa yang seseorang rasakan melalui kesadaran atau pengalamannya sendiri, tentang bagaimana perasaannya dan apa yang dia ketahui. Pemikiran Hegel sejatinya dipengaruhi oleh pemikiran Rene Descartes. Descartes mengatakan bahwa kita mengetahui sesuatu karena kita memikirkannya. Pernyataan terkenal Descartes "cogito ergo sum" berarti "Saya pikir inilah mengapa saya ada". Peran kesadaran dalam pengenalan sangat jelas. Awalnya, studi fenomenologi berkaitan dengan struktur kesadaran pengalaman. Oleh karena itu, fenomenologi sangat erat hubungannya dengan pengetahuan tentang sesuatu, asalkan terwujud dalam pengalaman. Fenomenologi didefinisikan sebagai pengalaman kita pada objek tertentu. Aliran tersebut sebenarnya adalah respons terhadap arus "Positivisme positif" yang menekankan dualisme antara tubuh dan pikiran atau kesadaran dan objek sadar. Sejauh menyangkut fenomenologi, dualisme ini tidak dapat dipertahankan, karena manusia sadar dan berpikir dengan tubuh mereka. Begitu pula kesadaran. Kesadaran selalu memiliki arti kesadaran akan sesuatu.

Dampak dari sikap dan pernyataan tersebut pada penelitian adalah bahwa satu-satunya cara kita dapat memahami pengalaman orang lain adalah dengan bertanya kepada mereka apa arti yang mereka berikan kepada orang lain. Bertanya tentang pengalaman mereka berarti mewawancarai mereka. Melalui wawancara, orang akan mengungkap makna dari pengalamannya. Aspek penting lainnya untuk mengerti makna pengalaman orang lain adalah terlibat langsung dalam situasi dan situasinya. Hanya dengan memahami konteks dan situasinya peneliti dapat mengerti dan memahami makna dari pengalaman ini. Memahami latar belakang dan lingkungan subjek penelitian berarti berada bersama mereka. Bersama berarti mengalami apa yang mereka alami. Orang yang belum mengalami gejala, kejadian, fakta atau kenyataan yang akan diteliti akan kesulitan memahami 
makna pengalaman orang lain. Jika tidak sesuai konteksnya, banyak nuansa yang tidak akan terasa. Dalam penelitian ini pendekatan analisis fenomenologi digunakan untuk memperhatikan dan menelaah desain khususnya dari Indonesia Timur berbasis kearifan lokal di era disrupsi 4.0. Selanjutnya melakukan penggalian data berupa bagaimana pemaknaan desain berbasis kearifan lokal dalam memberikan arti terhadap era disrupsi 4.0.

Penelitian ini menggunakan analisis berdasarkan teori representasi pengetahuan visual. dalam melakukan teknik analisis data. Menurut Solso, Maclin dan Maclin (2008), pengetahuan adalah penyimpanan, integrasi, dan organisasi informasi di dalam memori. Pengetahuan adalah informasi yang diproses, dan memori adalah sistem yang kita gunakan untuk mengakses pengetahuan itu. Representasi pengetahuan yang diperoleh manusia terbagi menjadi dua jenis, yaitu representasi pengetahuan bahasa dan representasi pengetahuan visual. Representasi pengetahuan visual biasanya berbicara tentang dongeng atau pembayangan mental (mental imagery). Pembayangan Mental diartikan sebagai penggambaran mental dari objek atau kejadian yang tidak ada selama proses pencitraan.

Langkah-langkah penelitian untuk mengetahui keberadaan kajian representasi visual dalam desain adalah sebagai berikut:

1. Mengumpulkan data primer dan sekunder dari buku-buku Perpustakaan Pusat dan Akademi Seni dan Desain, serta semua konten yang berkaitan dengan representasi buku teks dan manuskrip perpustakaan digital online.

2. Mengidentifikasi data jurnal ilmiah yang memuat artikel tentang ekspresi visual dan kearifan lokal yang berkaitan dengan objek penelitian.

3. Melakukan verifikasi data dan analisis data dari resensi buku, karya tulis ilmiah dan FGD penelitian representasi visual, khususnya penelitian desain dalam konteks kearifan lokal.

4. Merumuskan kesimpulan dan saran lebih lanjut tentang esensi penerapan desain visual dalam konteks kearifan lokal dalam mata kuliah desain estetika visual, dan penelitian sastra ekspresi visual dalam estetika oriental.

Tahapan dalam penelitian ini menggunakan tahapan seperti diagram alir yang telah digambarkan di atas yakni dimulai dari proses pengumpulan data lapangan, kemudian mencari data yang relevan dengan kajian yang akan dibahas, melakukan analisis tekstual dan kontekstual untuk mendapatkan hasil akhir dari penelitian sebagai pijakan dalam menyusun laporan akhir dan luaran untuk penelitian. Studi kasus yang digunakan adalah studi kasus tunggal yaitu penelitian yang difokuskan pada representasi visual yang mengalokasikan kearifan lokal yang diimplementasikan pada karya prasi oleh perancangan desainnya. Jenis penelitian ini juga termasuk studi kasus infomental yang mencermati secara menyeluruh dan mendalam yang tujuannya sebagai pengujian teori terhadap unsur-unsur tekstual dan kontekstual dalam tanda tanda yang tercipta serta teraplikasikan (Ratna, 2010:193).

\section{HASIL DAN PEMBAHASAN}

a. Lukisan Prasi telah ada dan berkembang pada zaman kerajaan Bali.

Konsep komunikasi dalam desain masa kini adalah menyampaikan karakteristik secara modern dan muda. Hal ini bertujuan untuk memperlihatkan originalitas dan kelokalan dari karya desain. Visualisasi yang diterapkan dalam karya bersifat modern namun tetap mempertahankan kearifan lokal. Kearifan lokal merupakan pandangan dan pengetahuan tradisional yang menjadi acuan perilaku dan diturunkan 
secara turun-temurun guna memenuhi kebutuhan dan tantangan kehidupan sosial. Kearifan lokal memiliki fungsi dan makna dalam masyarakat, tidak hanya melindungi sumber daya alam dan sumber daya manusia, tetapi juga menjaga adat istiadat dan budaya, serta bermanfaat bagi kehidupan (Permana 2011: 68). Mengacu pada pernyataan tersebut, pemikiran dan selera masyarakat Bali telah menghasilkan banyak objek yang menunjukkan kearifan lokal dan merupakan respon positif untuk menyelaraskan kebutuhan kegiatan dengan lingkungan. Contohnya adalah karya seni di atas daun lontar yang disebut prasi.

Menurut Suwidja, (1979:4-6) bahwa prasi adalah ilustrasi yang terdiri dari gambar dengan bentuk wayang yang dilengkapi dengan penjelasan tulisan (naskah cerita) dengan huruf Bali di atas daun lontar, lontar memiliki lebar 3 sampai $4 \mathrm{~cm}$ dengan panjang 40 sampai $70 \mathrm{~cm}$. Alat yang digunakan untuk menoreh tulisan maupun gambar sejenis pisau yang disebut pengutik atau pangrupak.

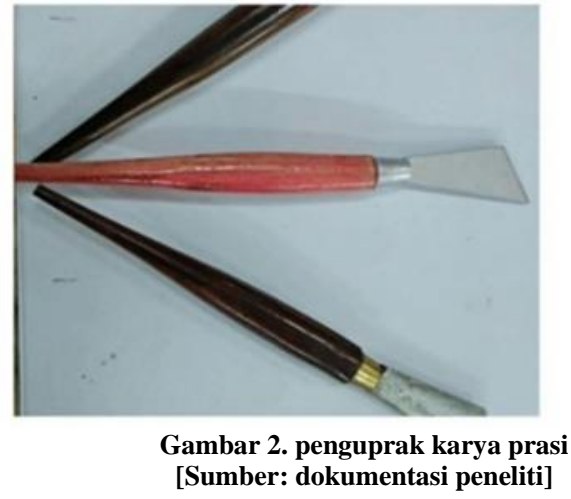

Terbuat dari baja dan ujung yang runcing harus berbentuk segitiga agar goresan dapat diatur lebih tebal atau tipis. Lebar tulisan Pangrupak sekitar 1,5 cm, dan lebar untuk lukisan 0,5-1 $\mathrm{cm}$. Seni prasi merupakan karya seni yang unik karena diaplikasikan pada daun lontar yang dihias dengan bentuk klasik, terkadang disertai teks pendek dengan menggunakan huruf Bali (sastra). Seni lukis prasi diyakini ada dan berkembang sejak era kerajaan Bali. Hal ini didukung oleh pernyataan Suardana mengutip Agastia (1994),membuktikan bahwa sejarah sastra Bali yang berkembang pada akhir abad ke-15 dan kemudian melejit pada abad ke-16. Semasa Giegle menjabat di pemerintahan klungkung, seni prasi menjadi salah satu bentuk seni sastra dalam bentuk seni rupa, sehingga digunakan sebagai media informasi tentang ajaran agama, dan sangat mungkin berkembang pada saat itu. Lukisan prasi pada dasarnya mengadopsi bentuk yang dapat dipersepsikan sesuai dengan cerita yang disampaikan. Sebagai contoh dari kakawin Ramayana, gambar Prasi dibuat berdasarkan cerita Ramayana dan tokoh lainnya. Orang dan benda-benda lain yang memiliki nilai religius, magis dan simbolis dan merupakan benda yang disukai dan dibutuhkan banyak orang.

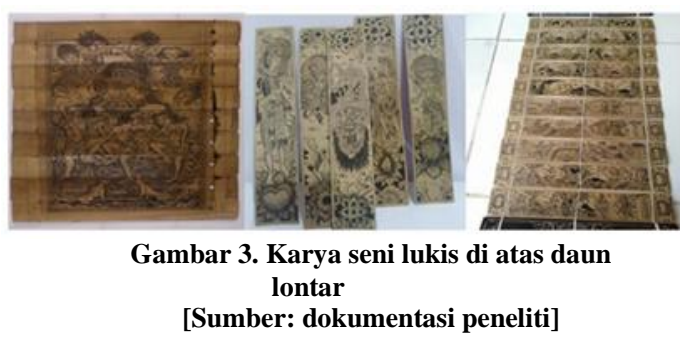

Sejak dulu, masyarakat Bali telah memahami pentingnya menyimpan data tertulis dalam bentuk manuskrip. Salah satu bahan yang digunakan sebagai medianya adalah daun lontar. Seperti orang Indonesia lainnya, orang Bali pada masa lalu juga memiliki budaya menulis di atas daun lontar. Tradisi tersebut berkembang hingga hari ini, yang dikenal sebagai prasi. Sebagai seni ilustratif, prasi merupakan karya visual yang penuh akan simbolisme dalam cerita yang ingin disampaikan oleh pelukisnya. Lukisan prasi pada dasarnya mengadopsi bentuk yang dapat dipersepsikan sesuai dengan cerita yang disampaikan. Bentuk wayang dan benda lain yang memiliki nilai religius, magis dan simbolis merupakan benda yang disukai dan diminati banyak orang. Di 
era 4.0 ini perkembangan bentuk, pengemasan dan cara-cara kreatif lainnya sudah menjadi hal yang lumrah. Karena beberapa karya dibuat berdasarkan pesan yang ingin disampaikan oleh peminat karya tersebut, meskipun dengan tokoh di luar kebiasaan. Fenomena tersebut sedikit membuat fungsi prasi saat ini telah menyimpang dari fungsi aslinya. Sekarang, prasi telah semata-mata menjadi objek koleksi dan tidak ada hubungannya dengan fungsi asli prasi.

\section{b. Karya Prasi di era disruptif 4.0}

Perkembangan teknologi tidak hanya berdampak negatif bagi karya seni, namun juga memberikan dampak positif yaitu memperoleh efisiensi dan optimalisasi dengan berbagai cara, termasuk efisiensi dan optimalisasi area penyimpanan serta keamanan dari berbagai bencana.

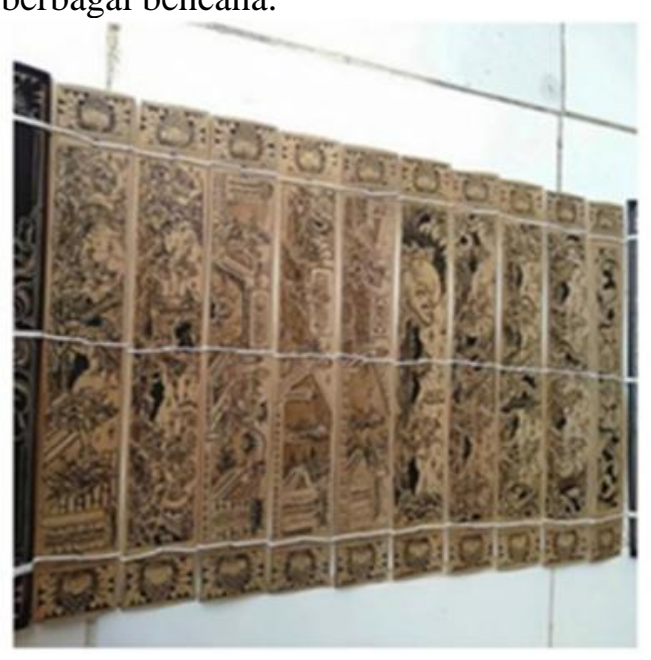

Gambar 4. karya prasi kontemporer [Sumber: dokumentasi penulis]

Pemanfaatan media digital dipandang paling tepat untuk menyelamatkan lontar Prasi karena tidak akan pernah mengalami kerusakan seperti lontar Prasi yang terbuat dari daun tal, bahan alami yang mudah mengalami kerusakan yang diakibatkan oleh cuaca, serangga serta penempatan yang kurang bagus. Dalam melestarikan karya prasi teknologi yang ada sangat membantu untuk mengalokasikan proses perekaman karya menuju digital.
Proses perekaman lontar Prasi ini dilakukan dengan alat bantu perekam (scanner), dengan menggunakan scanner resolusi tinggi sehingga keaslian dari warna dan gambar serta tulisan yang ada masih bisa dilihat dengan baik. Teknik ini digunakan karena scanner dapat membaca dengan sangat akurat baik dari warna Lontar maupun tekstur yang ada pada Lontar. Apabila sudah dilakukan dengan merekam lontar Prasi ke dalam media digital Langkah selanjutnya adalah memindahkannya ke dalam buku yang diharapkan dapat menjadi media pelestarian lontar Prasi terutama lontar Prasi yang sudah lapuk dan memerlukan perawatan yang intensif. Scanning isi lontar Prasi ke media buku bertujuan untuk menduplikasi lontar Prasi tersebut sehingga yang asli tidak mengalami kerusakan dan dapat bertahan lebih lama lagi, selain memungkinkan untuk didokumentasikan secara digital. Dengan demikian pemanfaatan teknologi digitalisasi di era disrupsi bisa dialokasikan untuk mempertahankan eksistensi karya prasi dan menyebarluaskan informasi kepada masyarakat luas sehingga eksistensi karya prasi tetap terjaga.

\section{SIMPULAN}

Masyarakat Bali masa lalu memiliki budaya tulis di atas daun lontar. Tradisi ini masih terus berlanjut hingga sekarang, yang lebih dikenal dengan sebutan prasi. Sebagai seni ilustratif, seni lukis prasi merupakan karya seni yang kental akan simbolisme dalam cerita yang ingin disampaikan oleh sang pencipta. Lukisan prasi pada dasarnya mengadopsi bentuk yang dapat divisualkan sesuai dengan cerita yang ingin disampaikan. Tokoh wayang dan benda lain yang memiliki nilai religi, spiritual, magis dan simbolik adalah benda-benda yang disukai dan banyak diminta. Di tengah berkembangnya era digital seperti saat ini, yang segalanya serba canggih dan tanpa batas, banyaknya karya-karya modern 
seperti kartun, film animasi membuat prasi seakan tidak punya ruang. Walaupun demikian, prasi masih tetap eksis dengan kearifan lokalnya sebagai kebudayaan dari bali dengan inovasi digitalisasi untuk eksistensi di era disrupsi 4.0 yang terjadi saat ini.

\section{DAFTAR PUSTAKA}

Band em, Made.1996. Heroisme dalam Sastra Babad di Bali Sebagaimana yang Tampak pada Pertunjukan Topeng, "Mudra", tahun IV: 7

Clark, Moustakas. 2002. Phenomenological Research Methods, California: SAGE,1994. Daymon, Holloway. MetodeMetode Riset Kualitatif dalam Public Relation dan Marketing Komunikasi. Jogyakarta

Dru, J.-M.2007.How Disruption Brought Order: the story of a winning strategy in the world of advertising. New York: St. Martin's Press.

Gautama, Wayan Budha.2007. Kesusastraan Bali: Cakepan Mlajahin Kesusastraan Bali. Gianyar: Paramita Surabaya.

National electronic Library for Health. 2003. Can walking make you slimmer and healthier? (Hitting the headlines article) [Online] (Updated 16 Jan 2005) URL: http://www.nhs.uk.hth.walking [Diakses pada 10 April 2020

Piliang, Yasraf Amir. 2005. "Menciptakan Keunggulan Lokal untuk Merebut Peluang Global: Sebuah Pendekatan Kultural". Denpasar: Makalah Seminar Seni dan Desain Institut Seni Indonesia Denpasar

Raharja.1999."Makna Ruang Arsitektur Pertamanan Peninggalan Kerajaan Kerajaan di Bali Sebuah Pendekatan

Hermeneutik"(Thesis). Bandung:Pa scasarjana Magister Desain 1TB

Ratna, Nyoman Kutha. 2010. Metodologi Penelitian: Kajian Budaya dan ilmu Sosial
Humaniora Pada Umumnya. Pustaka Pelajar: Yogyakarta

Ricoeur, Paul.1974. The Conf/icict of Interpretations.Evanston:Nortwest ern University Press

Solso,Maclin,Maclin.2008.Psikologi Kognitif. edisi kedelapan. Jakarta: Erlangga

Sutrisno, Andika Agung.2018. Seminar Antar Bangsa : Seni Budaya dan Desain • STANSA 2018. EFEKTIFITAS MEDIA PERIKLANAN DENGAN MEMANFAA TKAN POINT OF CONTACT, Vol. 3, pp. 15-20).

Suwidja, I Ketut.1979. Mengenal Prasi. Singaraja: Gedong Kirtya.

Wiwana, I Nyoman. 2010. Bentuk Seni Lukis Prasi 1 [online] (update 24 sep 2010)URL:https://www.isidpsac.i $\mathrm{d} /$ berita/bentuk-seni-lukis-prasi-i/ [dakses pada 13 April 2020 